\title{
IMPROVED GENERATION QUALITY OF AN ISOLATED WIND DRIVEN INDUCTION GENERATOR USING ARTIFICIAL NEURAL NETWORK
}

Yehia S. Mohamed

Electrical Eng. Dept.,

Faculty of Engineering, El-Minia University, ElMinia, Egypt
B. M. Hasaneen

Electrical Eng. Dept.,

Faculty of Engineering, Al-Azhar University, Qena, Egypt
Mohamed Abd-ElHakeem Mohamed

Electrical Eng. Dept., Faculty

of Engineering, Al-Azhar

University, Qena, Egypt

(Received March 10, 2010 Accepted March 28, 2010).

This paper presents the improvement of generation quality for a wind energy conversion scheme using artificial neural network (ANN). High generation quality means that, the induction generator generate voltages and frequency at nominal specified values, under all operating conditions, determined by various wind speeds and loads. The scheme consists of a three-phase induction generator driven by a horizontal axis wind turbine and interfaced to an isolated load. A static VAR compensator (SVC) is connected at the induction generator terminals to regulate its voltage. The mechanical power input is controlled by regulating the blade pitch-angle. Both blade pitch-angle and firing angle are adjusted using an ANN to improve the generation quality for a wind energy conversion scheme. The proposed ANN training is based on suitable values of SVC firing angles and blade pitch-angles of the wind turbine, for achieving a high generation quality at different operating conditions. The training data is obtained by using Newton-Raphson method to generate voltages and frequency at nominal specified values. The simulation results prove that, the wind energy conversion scheme, with the proposed ANN, gives good power generation quality over wide range of wind speeds and loads.

\begin{tabular}{|ll}
\hline & \\
$G_{r}$ & Gear box ratio \\
$I_{c o m}$ & SVC current \\
$I_{l}$ & Load current \\
$I_{s}$ & Stator current \\
$P$ & Number of pole pairs \\
$R_{l}$ & The load resistance \\
$R_{r}$ & Rotor resistance referred to stator \\
$R_{s}$ & Stator resistance \\
$S$ & Machine slip \\
$T_{g}$ & Induction generator torque \\
$T_{t}$ & Wind turbine torque \\
$V_{g}$ & The air gap voltage \\
$V_{s}$ & The stator terminal voltage \\
\hline
\end{tabular}




\section{INTRODUCTION}

Recently, there has been growing a global use of induction machines in wind power generation. The self-excited induction generator (SEIG), due to its high reliability, robustness, lower cost and less maintenance requirements, etc., is highly suitable for this application. The SEIG has been increasing used in renewable energy systems, which employ wind or mini-hydro power [1]. A reliable and simple method of starting the induction generator is to use the fixed excitation capacitor bank [2-3]. The SVC which consist of fixed capacitor in parallel with controlled reactor, is used for voltage regulation purpose [4-5]. Artificial neural network has been employed to adapt the value of the excitation capacitor based on steady state analysis [6].

Steady-state analysis of SEIG is of interest, both from the design and operational points of view. In an isolated power system, both the terminal voltage and frequency are unknown and have to be computed for a given speed, capacitance, and load impedance. A large number of articles have appeared on the steady-state analysis of the SEIG [7]-[10].

In [10], steady-state analysis and performance of SEIG, driven by regulated and unregulated turbines, using Newton-Raphson have been presented.

In [11], an attempt has been made to present a simple model to control the output voltage and frequency in case of SEIG under different operating conditions. It was realized that rotor resistance control for a wound rotor machine results in to a constant voltage constant frequency operation.

Many investigations were reported [2-11], about steady state analysis and control of SEIG, but no attention was paid to the effect of the nonlinear characteristic of wind turbine on these analysis. On the other hand, some of these papers [6-11] were not interested in the full identification of SVC of steady state analysis of SEIG. Therefore, the problems of poor generation quality are still unsolved. This motivates the authors to investigate how significant the effect of nonlinear characteristic of wind turbine and the full identification of SVC on the steady state analysis and control of SEIG for achieving the high generation quality have been investigate.

This paper presents the improvement of generation quality for a wind energy conversion scheme using artificial neural network (ANN). High generation quality means that, the induction generator generate voltages and frequency at the nominal specified values under all operating conditions as determined by various wind speeds and loads. The scheme consists of a three-phase induction generator driven by a horizontal axis wind turbine and interfaced to an isolated load. A static VAR compensator (SVC) is connected at the induction generator terminals to regulate its voltage. The mechanical power input is controlled by regulating the blade pitch-angle. Both blade pitch-angle and SVC firing angle are adjusted using an ANN to improve the generation quality for a wind energy conversion scheme. The proposed ANN is training based on suitable values SVC firing angles and blade pitch-angles of the wind turbine, for achieving a high generation quality at different values of operating condition. The training data is obtained, using Newton-Raphson method to generate voltages and frequency at nominal specified values. The simulation results prove that, the wind energy conversion scheme with the proposed ANN gives good power generation quality over wide range of wind speeds and loads. 


\section{DESCRIPTION OF THE SYSTEM}

Figure 1 shows a wind energy system connected to an isolated load via a static VAR compensator . It consists of a horizontal axis variable pitch wind turbine which drives a SEIG, a fixed capacitor -thristor controlled reactor (FC-TCR) compensator connected at the generator terminal. The terminal voltage depends on rotor speed, SVC equivalent impedance and load resistance while the stator frequency depends mainly on the rotor speed. In this paper, both blade pitch-angles and thristor firing angles are adjusted using ANN to improve the generation quality for a wind energy conversion scheme at all operating conditions.

HAWT

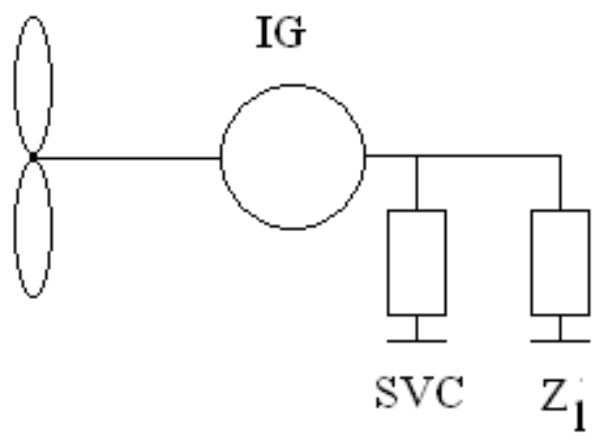

Figure 1: Schematic representation of wind energy system

\subsection{Wind turbine model}

The wind turbine is characterized by non dimensional curves of the power coefficient $\left(\mathrm{C}_{\mathrm{p}}\right)$ as a function of both tip speed ratio $(\lambda)$, and the blade pitch angle $(\beta)$,. The tip speed ratio can be defined as the ratio of angular rotor speed of the wind turbine to the linear speed at the tip of blades to the speed of the wind. It can be expressed as follows:

$\lambda=\frac{\omega_{t} R}{V_{w}}$

Where

$\omega_{t}=\frac{\omega_{r}}{P G_{r}}$

And $\mathrm{R}$ is the Wind turbine rotor radius.

Also, the developed torque by the blades is given by :

$T_{t}=\frac{0.5 \rho A R C_{p} V_{w}^{2}}{\lambda}$

Where $\rho$ is the air density and A is the swept area by the blades and

$C_{p}=(0.44-0.0167 \beta) \sin \left(\frac{\pi(\lambda-3)}{15-0.3 \beta}\right)-0.00184 \beta(\lambda-3)$ 


\subsection{Steady state model of an induction generator}

The equivalent circuit of an induction machine can be represented in terms of three impedances as shown in figure 2, these impedances are given by :

$$
\begin{aligned}
& Z_{r}=\left(\frac{R_{r}}{S}+j X_{l r}\right) \\
& Z_{s}=\left(R_{s}+j X_{l s}\right) \\
& Z_{m}=\left(j X_{m}\right)
\end{aligned}
$$

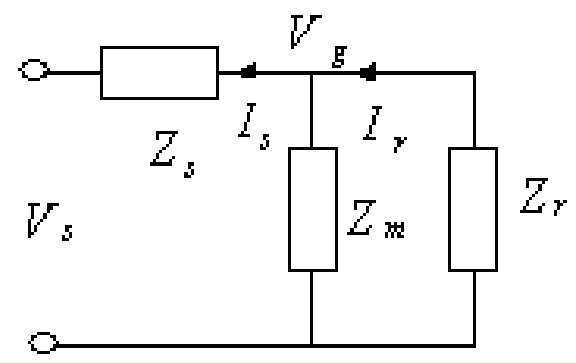

Figure 2: Circuit model of an induction machine

The rotor current vector is expressed as:

$$
\overrightarrow{I_{r}}=\frac{-\vec{V}_{g}}{Z_{r}}
$$

The shaft torque of an induction generator is defined as:

$$
T_{g}=-3 I_{r}^{2}\left(\frac{R_{r}}{\omega_{r} S}\right)(1-S)
$$

\subsection{Static VAR compensator model}

The SVC is properly connected across the induction machines' stator terminals. In this study, the FC-TCR compensator is used to maintain a constant voltage at the generator terminals by continuous adjustment of the gating angle of the thyristor. The schematic representation of the SVC and its equivalent circuit are shown in Figure 3-a and Figure 3-b respectively. Using Fourier analysis, the fundamental component of the inductor current can be calculated by the following equation using Fourier analysis as [4-5]:

$$
I_{i}=\frac{V_{s}}{X_{l}}
$$

Where the TCR equivalent reactance $\left(X_{l}\right)$ is given by:

$$
X_{l}=\frac{\pi X_{l \max }}{2(\pi-\alpha)-\sin [(2(\pi-\alpha)]}
$$

The SVC equivalent impedance can be written as: 
$\vec{Z}_{c}=\frac{-j X_{l} X_{c}}{\left(X_{l}-X_{c}\right)}$

Where $Z_{\mathrm{c}}$ is a function in $\omega_{\mathrm{s}}$ and $\alpha$

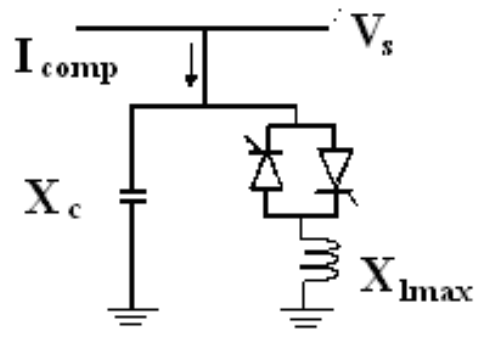

a

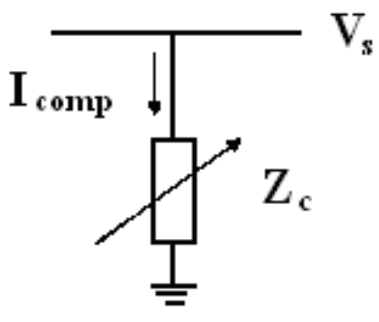

b

Figure 3: Model of Static VAR Compensator

\section{STEADY STATE MODEL OF AN INDUCTION GENERATOR CONNECTED TO AN ISOLATED LOAD}

The equivalent circuit of the system under study is shown in figure 4. This circuit is divided into three parts. The first part is a load which is represented as a resistance. The second part is the equivalent circuit of an induction generator. The third one is the link between the induction generator and the resistive load, which is .a fixed capacitor thristor-controlled reactor compensator. This is shown in figure 4 .

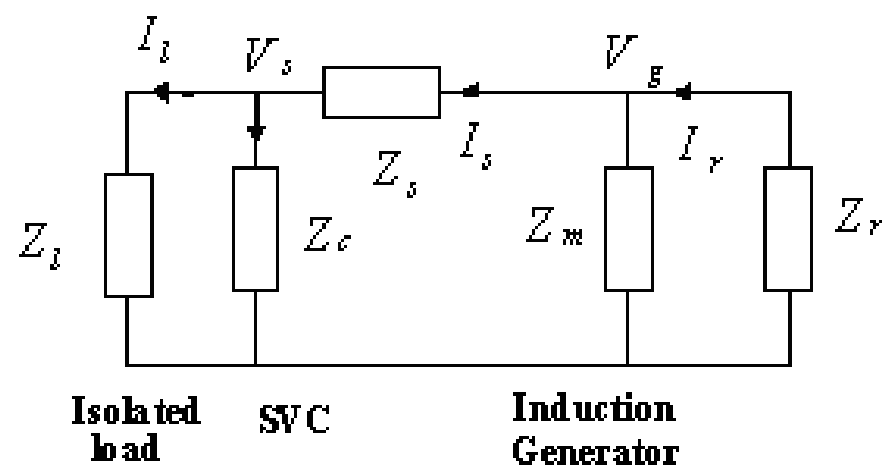

Figure 4: Equivalent circuit model of the system

The equivalent circuit of figure 4 can be simplified using series and parallel combination of the different impedances, as shown in figure 5. Where

$$
\begin{aligned}
& \vec{Z}_{x 1}=\frac{\vec{Z}_{r} \vec{Z}_{m}}{\left(\vec{Z}_{r}+\vec{Z}_{m}\right)} \\
& \vec{Z}_{x 2}=\frac{\vec{Z}_{l} \vec{Z}_{c}}{\vec{Z}_{l}+\vec{Z}_{c}}+\vec{Z}_{s}
\end{aligned}
$$




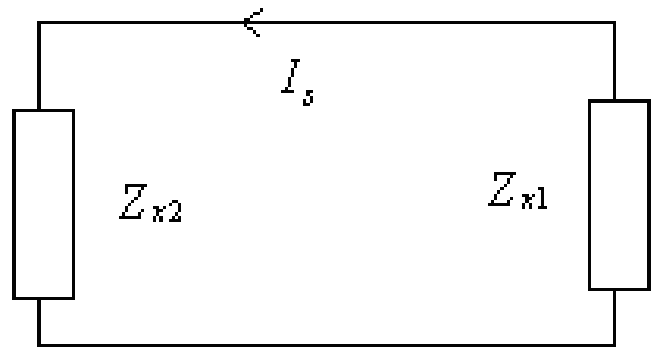

Figure 5: Simplified equivalent circuit model of the system

Applying mesh loop method to the circuit in figure 5, this yields.

$$
\left(\vec{Z}_{x 1}+\vec{Z}_{x 2}\right) \vec{I}_{s}=0
$$

Equation (10) has complex coefficients; that can be separated into real and imaginary parts, which are both equated to zero. Let the real and imaginary parts of equation (10) be denoted by $f_{1}$ and $f 2$ respectively

$$
\begin{aligned}
& f_{1}=\operatorname{Re} \operatorname{al}\left(\vec{Z}_{x 1}+\vec{Z}_{x 2}\right)=0 \\
& f_{2}=\operatorname{Im} \operatorname{age}\left(\vec{Z}_{x 1}+\vec{Z}_{x 2}\right)=0
\end{aligned}
$$

Neglecting the rotational loss torque, the turbine shaft torque $\left(T_{t}\right)$ is equal to the generator torque $\left(\mathrm{T}_{\mathrm{g}}\right)$ in steady state. The difference between these torques denoted by $f_{3}$. is equal to zero ,i.e.

$$
f_{3}=T_{t}-T_{g}=\mathrm{O}
$$

\section{PARAMETER DETERMINATION FOR HIGH GENERATION QUALITY}

In this study, the FC-TCR compensator is used to maintain the voltage constant at the generator terminals by continuous adjustment of the gating firing angle of the thyristor $(\alpha)$. The mechanical power input is controlled by regulating the blade pitch-angle $(\beta)$. In the next section, both parameters ( $\alpha$ and $\beta$ ). are adjusted using an ANN to improve the generation quality for a wind energy conversion scheme. The proposed ANN training is based on suitable values of these parameters at all operating conditions determined by various wind speeds and loads, which are obtained by using NewtonRaphson method. The determination of these parameters $(\alpha$ and $\beta$ ) are described in the following steps:

Step 1: The parameters ( $\alpha$ and $\beta$ ) are determined based on equations (11)-(13) using Newton-Raphson method. To apply the Newton-Raphson method for obtaining these parameters, the values of voltage and frequency in equations (11)-(13) are considered constant at nominal specified values under specified values of wind speeds $\left(\mathrm{V}_{\mathrm{w}}\right)$ and load resistance $\left(\mathrm{R}_{\mathrm{l}}\right)$. The elements of the resulting Jacobian matrix $(\mathrm{J})$ are obtained by differentiating equations (11)-(13) with respect to the SVC equivalent impedance $\left(Z_{c}\right)$, electrical rotor angular speed $\left(\omega_{\mathrm{r}}\right)$ and blade pitch-angle $(\beta)$, and are collected into portioned vector matrix forms, as: . 


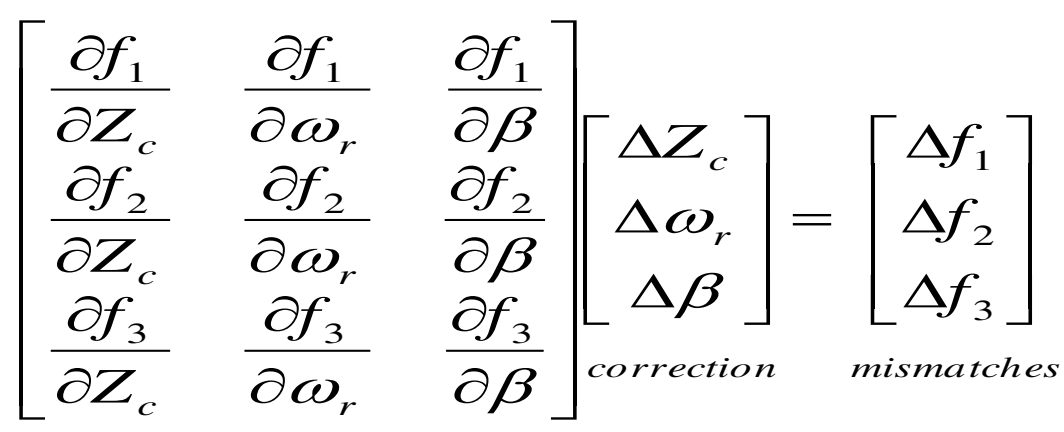

Jacobian

Step 2: The initial mismatch vector and the inverse of Jacobian matrix are calculated corresponding to the initial values of $Z_{c}, \omega_{r}$ and $\beta$ for specified operation and are used for obtaining initial correction vector as follows:

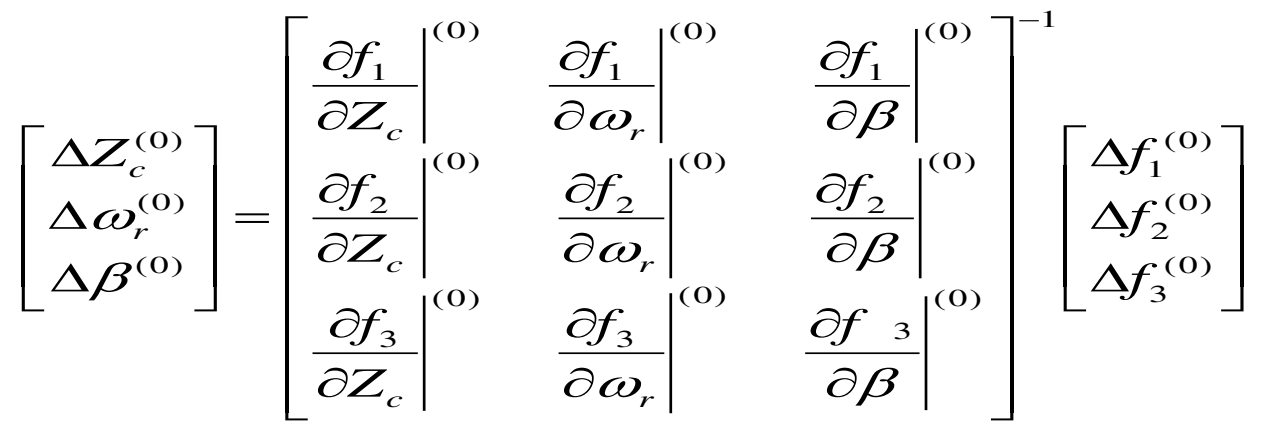

Step 3: The initial corrections $\left(\Delta \mathrm{Z}_{\mathrm{c}}, \Delta \omega_{r}\right.$ and $\left.\Delta \beta\right)$ are added to initial estimated values of $Z_{c}, \omega_{r}$ and $\beta$ to obtain their new values first iteration, the general form can be written as:

$$
\begin{aligned}
& Z_{c}^{(k+1)}=Z_{c}^{(k)}+\Delta Z_{c}^{(k)} \\
& \beta^{(k+1)}=\beta^{(k)}+\Delta \beta^{(k)} \\
& \omega_{r}^{(k+1)}=\omega_{r}^{(k)}+\Delta \omega_{r}^{(k)}
\end{aligned}
$$

Step 4: The process of iteration is repeated until the values of these correction are minimized. At this condition, the values of $\left(Z_{c}\right.$, and $\left.\beta\right)$ are used for high generation quality of a wind energy conversion scheme under specified values of wind speeds $\left(\mathrm{V}_{\mathrm{w}}\right)$ and load resistance $\left(\mathrm{R}_{\mathrm{l}}\right)$.

Step 5: The thyristor gate-firing angle $(\alpha)$ of the SVC is calculated based on equation (9) using the obtained value of the SVC equivalent impedance $\left(Z_{c}\right)$ from the NewtonRaphson method.

Step 6: The above steps are repeated over a wide range of operating conditions $\left(\mathrm{V}_{\mathrm{w}}\right.$ and $R_{l}$ ) to calculated suitable values of $\alpha$ and $\beta$ for the best generation quality of a wind energy conversion scheme. This obtained values of $\alpha$ and $\beta$ and their corresponding values of $\mathrm{V}_{\mathrm{w}}$ and $\mathrm{R}_{1}$ are used as a training data for designing ANN, which discussed in the next section 


\section{THE PROPOSED ARTIFICIAL NEURAL NETWORK FOR HIGH GENERATION QUALITY}

In this paper, the proposed ANN has employed to improve of the generation quality for a wind turbin-SEIG scheme connected to an isolated load. The functions of MATLAB are used to create a one-layer tan- sigmoid network with two inputs, namely the wind speed $\left(\mathrm{V}_{\mathrm{w}}\right)$ and load resistance $\left(\mathrm{R}_{\mathrm{l}}\right)$, and two outputs, namely the firing angle $(\alpha)$ and the blade pitch angle ( $\beta)$ which are required for achieving . The suitable values of $\alpha$ and $\beta$ for the best generation quality, are calculated using Newton-Raphson method which is described in the pervious section. The obtained values of $\alpha$ and $\beta$ and their corresponding values of $\mathrm{V}_{\mathrm{w}}$ and $\mathrm{R}_{1}$ are used as a training data for designing the proposed ANN as shown in figure 6.

\subsection{Operation Steps of artificial neural network}

The following steps describe the operation of an artificial neural network which is shown in figuer 6 :

Step 1: Nodes of the input layer receive signals from the collected data. Which are wind speed and resistance of the resistive load.

Inputs $=\left[\begin{array}{ll}\mathrm{V} & \mathrm{R}_{1}\end{array}\right]$

Step 2: Output of the input layer passes to hidden nodes through the weighted links, the resulting weight matrix between the hidden and input neurons is given by $\mathrm{W}_{1}$ and the hidden nodes biases are given by the $b_{1}$.

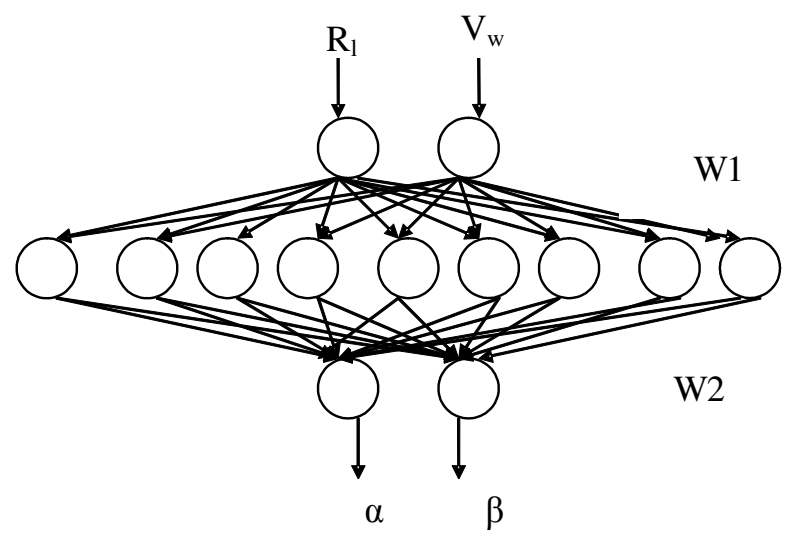

Figure 6: Structure of the proposed ANN for high generation quality.

Step 3: The output of hidden nodes results from input signal passing through the activation function (tan- sigmoid function). The hidden layer output vector of artificial neural network is $\mathrm{O}_{\mathrm{h}}$, where:

$\mathrm{O}_{\mathrm{h}}=\operatorname{tansig}\left(\mathrm{W}_{1} *\right.$ Inputs, $\left.\mathrm{b}_{11}\right)$

Step 4: Hidden layer outputs are sent to the output nodes through weighted links, the resulting weight matrix between the hidden and output neurons is given by $\mathrm{W}_{2}$ and the hidden nodes biases given by the $b_{2}$. 
Step 5: The artificial neural network output is obtained using another activation function (Linear activation function), the output vector of artificial neural network is Outputs, where:

Outputs=purelin $\left(\mathrm{W}_{2} * \mathrm{O}_{\mathrm{h}}, \mathrm{b}_{2}\right)$

Outputs $=[\alpha ; \beta]$

Equations (19)- (22) are used to describe the operation steps of the proposed ANN. The ability of the proposed ANN to obtaining the nominal values of voltage and frequency are checked in the next section using Newton-Raphson method.

\subsection{Checking the effectiveness of the proposed ANN for high generation quality}

To check the effectiveness of the proposed ANN for achieving a high generation quality, the obtained values of $\alpha$ and $\beta$ from the proposed ANN under specified values of $V_{w}$ and $R_{1}$ are used to check that, the values of terminal voltage and frequency $\left(, V_{g}\right.$ and $\left.\omega_{\mathrm{s}}\right)$ are at nominal values. The terminal voltage, frequency and speed $\left(\boldsymbol{\omega}_{\mathrm{s}}, \mathbf{V}_{\mathrm{g}}\right.$ and $\boldsymbol{\omega}_{r}$.) are determined based on equations (11)-(13) using Newton-Raphson method. To apply the Newton-Raphson method for obtaining the operating point $\left(\boldsymbol{\omega}_{\mathrm{s}}, \mathbf{V}_{\mathrm{g}}\right.$ and $\boldsymbol{\omega}_{\boldsymbol{r}}$.), the elements of Jacobian matrix are obtained by differentiating equations (11)-(13) with respect to the $\left(\mathbf{V}_{\mathbf{g}}\right),\left(\omega_{\mathrm{s}}\right)$ and $\left(\omega_{\mathrm{r}}\right)$, and are collected into portioned vector matrix forms as:

$$
\left[\begin{array}{lll}
\frac{\partial f_{1}}{\partial V_{g}} & \frac{\partial f_{1}}{\partial \omega_{s}} & \frac{\partial f_{1}}{\partial \omega_{r}} \\
\frac{\partial f_{2}}{\partial V_{g}} & \frac{\partial f_{2}}{\partial \omega_{s}} & \frac{\partial f_{2}}{\partial \omega_{r}} \\
\frac{\partial f_{3}}{\partial V_{g}} & \frac{\partial f_{3}}{\partial \omega_{s}} & \frac{\partial f_{3}}{\partial \omega_{r}}
\end{array}\right]\left[\begin{array}{c}
\Delta v_{g} \\
\Delta \omega_{s} \\
\Delta \omega_{r}
\end{array}\right]=\left[\begin{array}{c}
\Delta f_{1} \\
\Delta f_{2} \\
\Delta f_{3}
\end{array}\right]
$$

The inverse of the Jacobian matrix is calculated and is multiplied by the vector mismatch matrix which is determined according to the obtained values of $\alpha$ and $\beta$ for obtaining the operating point $\left(\boldsymbol{\omega}_{\mathrm{s}}, \mathbf{V}_{\mathrm{g}}\right.$ and $\boldsymbol{\omega}_{\mathrm{r}}$. $)$ using iterative iteration process as discussed previously.

\section{RESULTS AND DISCUSSION}

Digital simulation is carried out to investigate how the power generation quality of a wind turbin -SEIG scheme connected to an isolated load, is improved according to ANN. The data of the system under study is listed in Appendix 1.

The artificial neural network is trained using the input output pairs of the data by using analysis, which is discussed in section 4 . The training data is fed to Matlab Toolbox for calculating the values of the weights and biases of ANN.

The statistical data for ANN training are: no. of iterations $=10000$, max., Squared error $=0.001$, and learning rate $=0.001$.

The resulting weight matrix between the hidden and input neurons $\left(\mathrm{W}_{1}\right)$ and the hidden nodes biases matrix $\left(b_{1}\right)$ are given by: 


$$
\mathrm{W}_{1}=\left[\begin{array}{cc}
-23.496 & 4.3895 \\
-23.384 & 4.3758 \\
3.1308 & 0.016973 \\
3.286 & 0.0077554 \\
-8.897 & -0.37013 \\
13.491 & 2.9298 \\
-11.302 & 3.098 \\
-1.4646 & 4.6885 \\
9.3903 & 0.42227
\end{array}\right]^{t} \quad \mathrm{~b}_{1}=\left[\begin{array}{c}
14.228 \\
14.149 \\
-0.10955 \\
-0.61039 \\
2.2094 \\
-9.4845 \\
3.0596 \\
-2.7258 \\
-2.4878
\end{array}\right]
$$

The resulting weight matrix between the output and hidden neurons $\left(\mathrm{W}_{2}\right)$,, and also the output nodes biases matrix $\left(b_{2}\right)$ are given by:

$$
\mathrm{W}_{2}=\left[\begin{array}{cc}
0.055808 & 12.904 \\
-0.056091 & -12.964 \\
14.517 & -166.19 \\
-4.9819 & -0.10934 \\
8.6636 & -0.049872 \\
0.0028548 & -0.4367 \\
0.0008642 & -0.049872 \\
0.0059193 & -0.4367 \\
6.814 & -145.3
\end{array}\right]
$$$$
b_{2}=\left[\begin{array}{r}
-6.3592 \\
57.725
\end{array}\right]
$$

Figure 7 shows the variation of the blade pitch angles of wind turbine with the values of wind speeds which are obtained from the proposed ANN for achieving the high generation quality at constant load resistance value $\left(\mathrm{R}_{1}=1.0 \mathrm{p}\right.$.u $)$. From this figure, it will be noticed that, as the wind speed increases from $7 \mathrm{~m} / \mathrm{sec}$ to $24 \mathrm{~m} / \mathrm{sec}$ the value of blade pitch angle increases from $0^{0}$ to $19^{\circ}$ causing the mechanical input power to decrease and vice verse. Consequently, the effect of wind speed variations will be eliminated by adjusting the blade pitch angle using the proposed ANN.

Figure 8 shows the variation of the firing angle of SVC with the values of load resistances which are obtained from the proposed ANN for achieving the high generation quality at constant wind speed value $(15 \mathrm{~m} / \mathrm{sec})$. From this figure, it will be noticed that, as the load resistance increases from $0.8 \mathrm{pu}$. to $2.0 \mathrm{pu}$., the value of firing angle decreases from $173^{\circ}$ to $98^{\circ}$. This causes a reduction in the TCR equivalent impedance.. Consequently, the effect of load resistance variations will be eliminated by adjusting the firing angle using the proposed ANN.

To check the effectiveness of the proposed ANN for achieving high generation quality of system under study described by figure 1, the steady state performance have to be computed for a wide range of operating condition.

Figure 9 and figure 10 show the steady state variations of the generated frequency and voltage with the load resistance at the low value of the wind speed $\left(\mathrm{V}_{\mathrm{w}}=8 \mathrm{~m} / \mathrm{sec}\right)$ for the system under study with the proposed ANN. From these figure, the values of generated frequency and voltage have a good agreement with their target one. In addition, there are small deviations between the values of generated frequency and generated voltage with their target one at high values of load resistances. These deviations are acceptable compared with the international standards. 
The steady state variations of the generated frequency and voltage with the load resistance obtained using the proposed ANN are compared with target one at two different values of wind speeds $\left(\mathrm{V}_{\mathrm{w}}=15 \mathrm{~m} / \mathrm{sec}\right.$ and $\left.\mathrm{V}_{\mathrm{w}}=24 \mathrm{~m} / \mathrm{sec}\right)$ are shown in figures 11-14. These figures show that, the values of generated frequency and voltage have good matching with their target one. As the values of wind speed increases, the deviations between the values of generated frequency and voltage and their target one increases as shown in figure 13 and 14. All of these deviations are acceptable compared with the international standards.

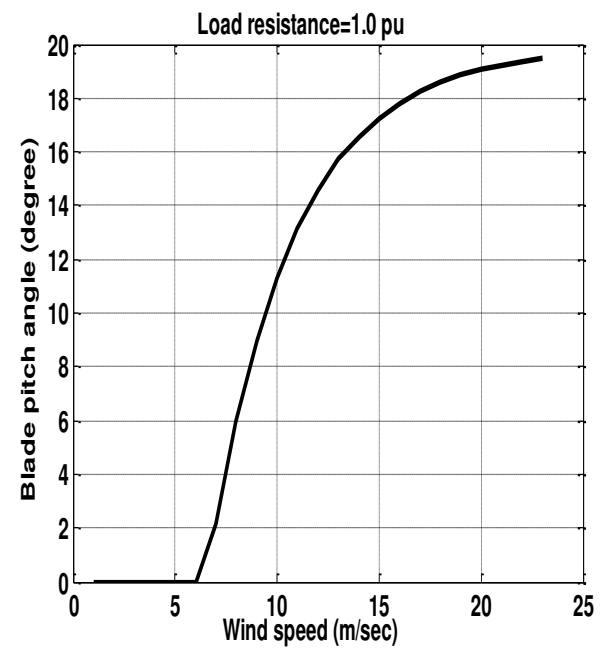

Figure 7: Variation of the blade pitch angle with the wind speed

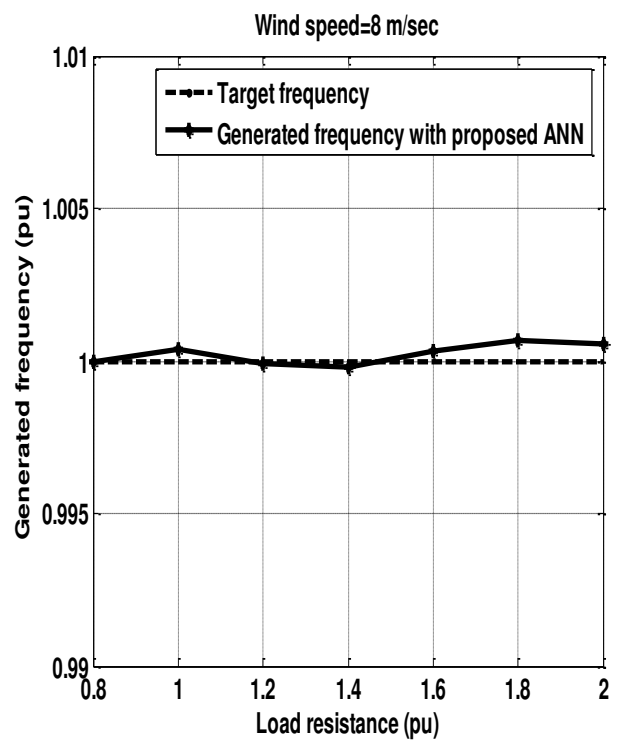

Figure 9: Variation of the generated frequency with the load resistance at low speed using the proposed ANN

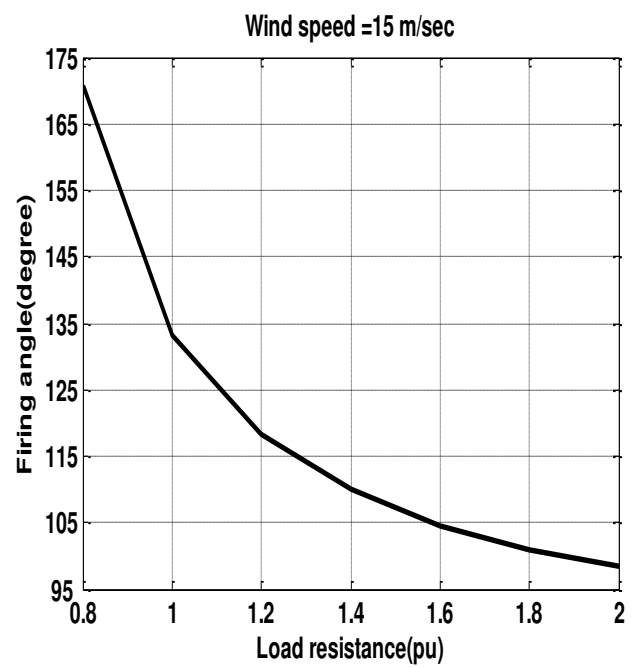

Figure 8: Variation of the firing angle with the load resistance

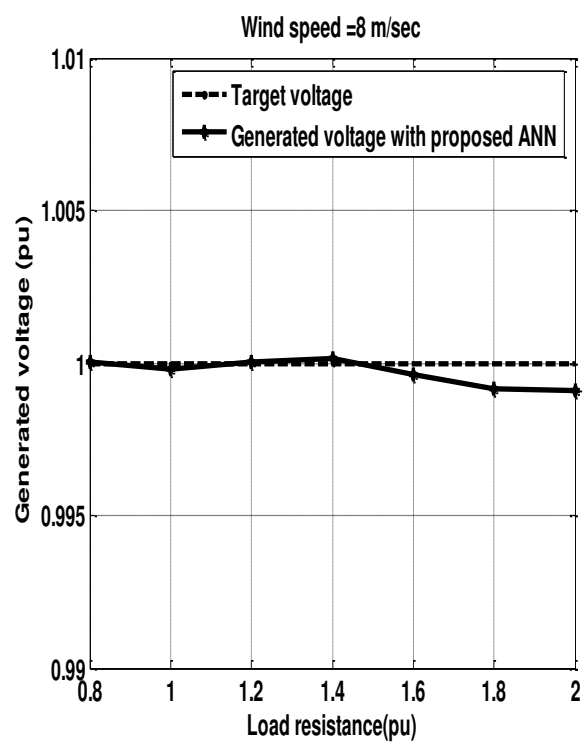

Figure 10: Variation of the generated voltage with the load resistance at low speed using the proposed ANN 


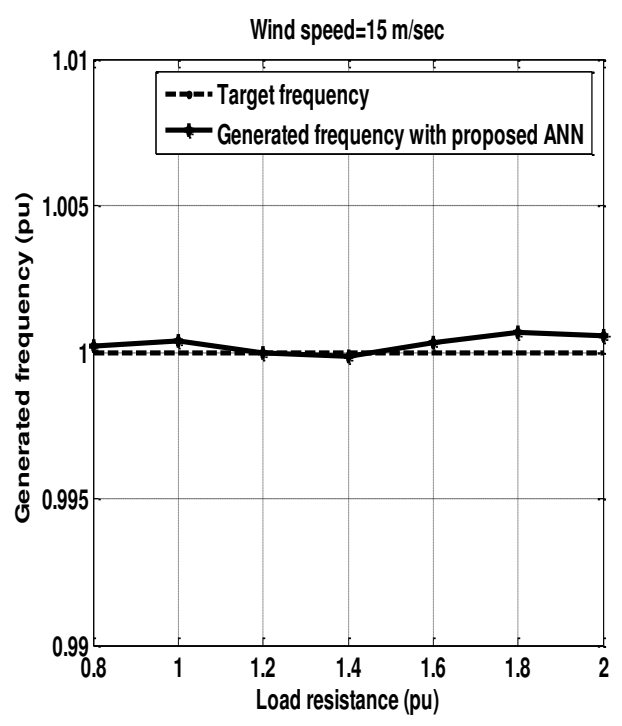

Figure 11: Variation of the generated frequency with the load resistance at rated speed using the proposed ANN

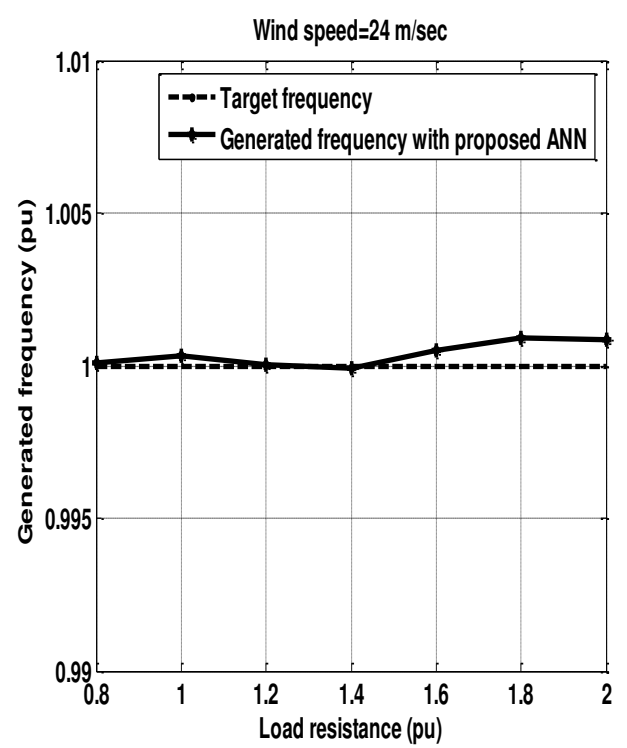

Figure 13: Variation of the generated frequency with the load resistance at high speed using the proposed ANN

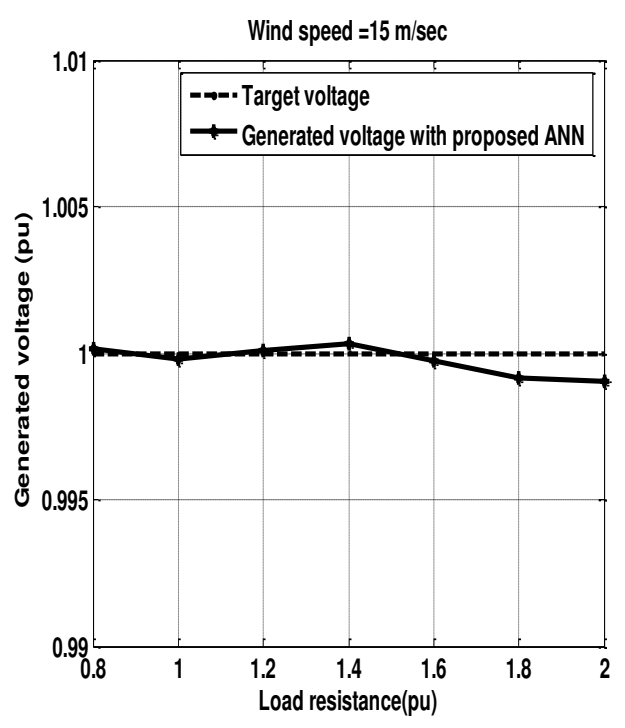

Figure 12: Variation of the generated voltage with the load resistance at rated speed using the proposed ANN

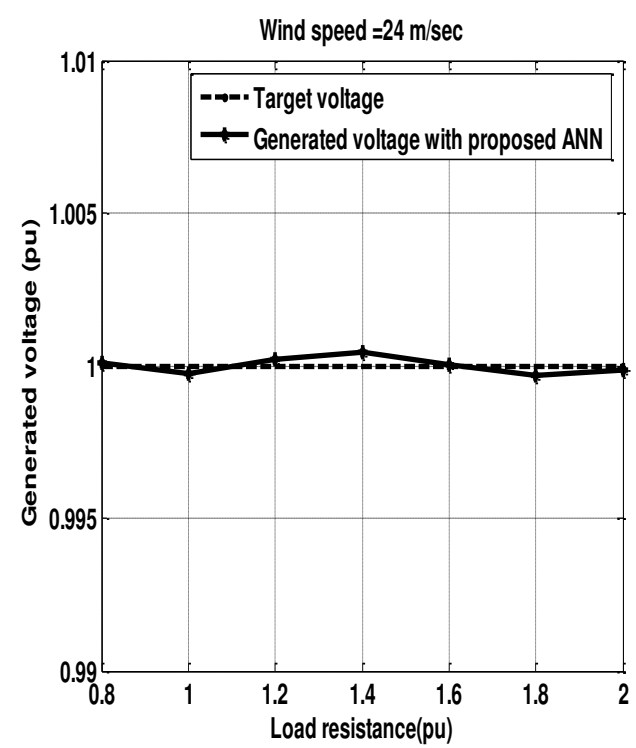

Figure 14: Variation of the generated voltage with the load resistance at high speed using the proposed ANN

\section{CONCLUSION}

This paper investigates the improvement of generation quality for a wind driven SEIG in steady state using ANN approach. The proposed ANN is training based on suitable values of static VAR firing angles and blade pitch-angles of the wind turbine for 
achieving high generation quality at different values of operating condition. The training data is obtained using Newton-Raphson method to generate voltages and frequency at nominal specified values. Digital simulations have been carried out in order to evaluate the proposed ANN for achieving high generation quality in steady state operation. The wind energy system with the proposed ANN are tested through different values of the load resistance and wind speed. From the present analysis one can draw the following main conclusions :

(1) The effect of nonlinear characteristic of wind turbine and the full identification of SVC parameters in the steady state analysis and control of SEIG are taken into consideration for achieving the high generation quality. These nonlinearities of system under study are treated using Newton-Raphson method.

(2) The effect of wind speed variations will be eliminated by adjusting the blade pitch angle using the proposed ANN to maintain the generated frequency at nominal specified value.

(3) The effect of load variations will be eliminated by adjusting the firing angle using the proposed ANN to maintain the generated voltage at nominal specified value

(4) The system with the proposed ANN gives high generation quality under all operating conditions determined by various wind speeds and loads.

\section{REFERENCES}

[1] R. C. Bansal, T. S. Bhatti, and D. P. Kothari, "A bibliographical Survey on Induction Generators for Application of Nonconventional energy systems," IEEE Trans. Energy Convers., Vol. 18 , No. 3 , pp. 433-439, Sep. 2003.

[2] N. H. Malik and A. A. Mazi, "Capacitive Requirements for Isolated Self Excited Induction Generators," IEEE Trans. Energy Convers., Vol. EC-2, No. 1, pp. 6269, Mar. 1987.

[3] L. Shridhar, B. Singh, C. S. Jha, B. P. Singh, and S. S. Murthy, "Selection of Capacitors for the Self Regulated Short Shunt Self-Excited Generator," IEEE Trans. Energy Convers., Vol. 10, No. 1, pp. 10-17, Mar. 1984.

[4] T.Ahmed K. Nishida, K. Soushin and M. Nakaoka "Static VAR Compensator based Voltage Control Implementation of Single-phase Self Excited Induction Generator “ Proc Inst. Eng-Generation, Trans mission, Distrib. ,Vol. 152.No2, pp 145-156, Mar. 2005

[5] T.Ahmed O. Nioro, E. Hiraki and M. Nakaoka "Terminal Voltage Regulation Characteristic by Static VAR Compensator for a Three-phase Self Excited Induction Generator “,” IEEE Trans. Ind . Appl., Vol. 40, No. 4, pp. 978-988, Jul. 2004.

[6] A .A. Hassan Y.S. Mohamed and A .M .Kassem, "A Neural Voltage Regulator for a Wind Driven Self Excited Induction Generator" MEPICON,2003 IEEE Shebin ELkom $9^{\text {th }}$ international Middel East Power systems conference p691. Dec.16-18, 2003

[7] D. K. Jain, A. P. Mittal, and B. Singh, "An efficient iterative technique for the analysis of self-excited induction generator,” J. Inst. Eng. (India), Vol. 79, No. 1, pp. 172-177, 1999.

[8] T. F. Chan, "Analysis of Self-Excited Induction Generators using an Iterative Method,” IEEE Trans. Energy Convers., Vol. 10, No. 3, pp. 502-507, Sep. 1995. 
[9] A. L. Alolah and M. A. Alkanthal, "Optimization based Steady State Analysis of Three Phase SEIG," IEEE Trans. Energy Convers., Vol. 15, No. 1, pp. 61-65, Mar. , 2000.

[10] S. M. Alghuwainem, "Steady-state Analysis of an Isolated Self-Excited Induction Generator Driven by Regulated and Unregulated Turbine," IEEE Trans. Energy Convers., Vol. 14, No. 3, pp. 718-723, Sep. 1999.

[11] K. S. Sandhu and Shelly Vadhera, "Steady State Operation of Self-Excited Induction Generator with Varying Wind Speeds," WSEAS Transactions on Circuits and Systems, Issue 1, Volume 2, 2008.

\section{APPENDIX 1}

\section{A. Induction Generator Parameters}

4 poles, $6.6 \mathrm{Kv}, 60 \mathrm{~Hz}$.

$\mathrm{X}_{\mathrm{m}}=4.161$ pu.; $\mathrm{X}_{1 \mathrm{~s}}=0.135$ pu.; $\mathrm{X}_{1 \mathrm{r}}=0.075$ pu. $; \mathrm{R}_{\mathrm{s}}=0.0059$ pu. $; \mathrm{R}_{\mathrm{r}}=0.0339$ pu.;

\section{B. Static VAR Compensator Parameters}

$\mathrm{X}_{\operatorname{lmax}}=3.5$ pu.; $\mathrm{X}_{\mathrm{c}}=2.5 \mathrm{pu}$.

\section{Wind Turbine Parameters}

Horizontal axis wind turbine (6 MW)

$\mathrm{R}=200 \mathrm{ft} ; \mathrm{G}_{\mathrm{r}}=103.6$

\section{تحسين جودة القرة الكهربيه لمولد حثي مدار بطاقة الرياح وموصل بحمل معزول باستخدام شبكات الذكاء الاصطناعي}

تبين هذه الدراسة كيفية تحسين جودة الإنتاج لوحدة التوليد المدارة بطاقة الرياح والتي تغذي حملا منعزلا

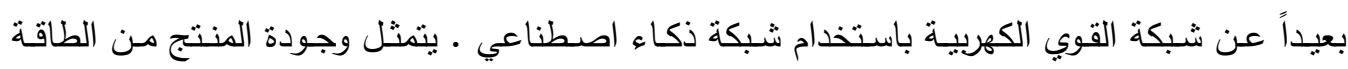

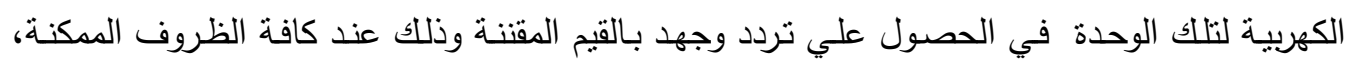

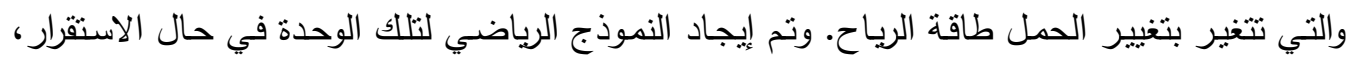

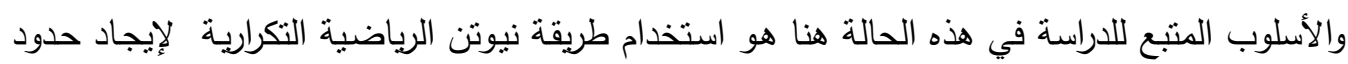
التتغيل التي يمكن أن تعدل تلك الوحدة في مداها، بحيث تحافظ علي جودة عاليه للطاقة الكهربية المنتجة، وعبر استخدام النتائج الني يتم الحصول عليها من تلك الطريقة الرياضية يتم تصميم شبكه

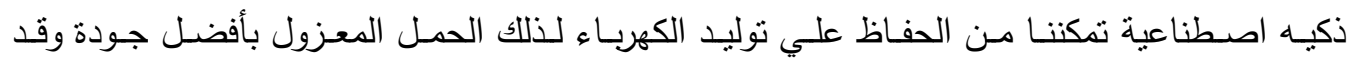

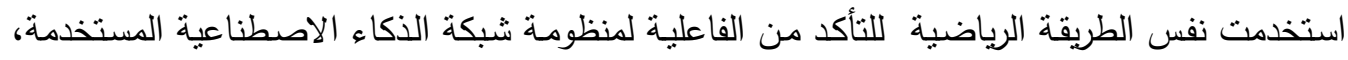
وقد تبين فاعلية ألثبكه العصبية المقترحة عند كافة ظروف التتغيل المحددة. 